\title{
Fundamentos Teóricos e Metodológicos do Ensino por Investigação
}

\section{Theoretical and Methodological Fundamentals of Investigative Teaching}

\section{Anna Maria Pessoa de Carvalho ${ }^{\circledR}$ Brasil}

Nas últimas décadas, orientamos no Laboratório de Pesquisa e Ensino de Física da Faculdade de Educação da Universidade de São Paulo (LAPEF) um conjunto de pesquisas sobre ensino, aprendizagem e formação de professores, tendo por base as atividades investigativas das Sequências de Ensino Investigativo (SEI), nos níveis Fundamental I e Médio. Isso resultou na constituição de um programa de pesquisa sobre ensino investigativo, cujos principais elementos são sintetizados neste artigo. Tal síntese enfatiza os resultados de nossas investigações, destacando muitos dos conhecimentos que temos produzido ao longo das últimas décadas. A partir daí, identificamos um dos problemas mais relevantes que nos desafiam atualmente: quando os professores aplicam nossas sequências de ensino investigativos, por que encontramos, com muito mais frequência, maior liberdade intelectual e construção do conhecimento científico pelos alunos nas aulas de Ciências do Fundamental I do que nas aulas de Física do curso médio? Considerando os conhecimentos e experiências desenvolvidos e vivenciados no LAPEF, levantamos algumas hipóteses sobre tal problema, esperando que futuras investigações sobre as mesmas - ou outras a elas relacionadas - possam contribuir para prosseguir nosso programa de pesquisa.

Palavras-chave: ensino por investigação; liberdade intelectual, problema investigativo, sequência de ensino investigativo, formação de professores.

During the last decades, we have conducted a set of studies on teaching, learning and teacher training in LAPEF a group of research on teaching, learning, and teacher training based on investigative activities of the Sequences of Investigative Teaching (SEI) in elementary and high school. This resulted in the constitution of a research program on investigative teaching, the main elements of which are summarized in this article. Such a synthesis emphasizes the results of our research highlighting many of the knowledge we have produced over the past few decades. From there, we identify one of the most relevant problems that challenge us today: "why do we very frequently find more intellectual freedom when teachers apply our investigative teaching sequences -and therefore greater construction of scientific knowledge by the students - in elementary level science classes than in high school physics classes?" Considering the knowledge 
and experiences developed and experienced in LAPEF, we raise some hypotheses about this problem, hoping that future research on them - or others related to them - may contribute to the continuation of our research program

Keywords: investigative teaching; investigative activities; sequence of investigative activities; research on investigative teaching; teacher training.

\section{Introdução}

No Laboratório de Pesquisa e Ensino de Física da Faculdade de Educação da Universidade de São Paulo (LAPEF), orientamos desde a década de 80 do século passado, mestrados e doutorados de dois Programas de Pós-Graduação da Universidade de São Paulo: o da Faculdade de Educação, na linha de pesquisa Ensino de Ciências e o Interunidades, dos Institutos de Física, Química, Biologia e Faculdade de Educação. Já desenvolvemos vários Programas de Pesquisas como o desenvolvimento psicogenético dos conceitos de Física, isto é, pesquisamos como os conceitos de Física (visão, velocidade, aceleração, velocidade angular, quantidade de movimento, campo gravitacional e elétrico e decomposição) que ensinamos são construídos pelos alunos e a influencia da História das Ciências e da Resolução de Problemas Abertos na construção dos conhecimentos científicos pelos alunos (Carvalho et al., 1993).

Depois de pesquisar o ensino e a aprendizagem nesses contextos, nosso programa de pesquisa atual envolve estudar a relação entre o ensino e a aprendizagem em sala de aula e a formação de professores de Ciências para o Ensino Fundamental, e de Física para o Ensino Médio, no contexto do ensino por investigação (Carvalho, 2013). Definimos como ensino por investigação o ensino dos conteúdos programáticos em que o professor cria condições em sua sala de aula para os alunos:

- pensarem, levando em conta a estrutura do conhecimento;

- falarem, evidenciando seus argumentos e conhecimentos construídos;

- lerem, entendendo criticamente o conteúdo lido;

- escreverem, mostrando autoria e clareza nas ideias expostas.

Em consequência disso, quando avaliamos o ensino que propomos, não buscamos verificar somente se os alunos aprenderam os conteúdos programáticos, mas se eles sabem falar, argumentar, ler e escrever sobre esse conteúdo.

Nosso grande problema dessas últimas décadas foi estudar a aprendizagem dos alunos (como definido acima) relacionando essa aprendizagem com a maneira como o ensino era realizado. Estudamos essa relação tanto no ensino Fundamental como no Médio.

Esse grande problema foi dividido em problemas menores (mestrados e doutorados), que estudaram a aprendizagem dos alunos em diversas atividades 
investigativas.

Para o desenvolvimento de nossas pesquisas, planejamos Atividades Investigativas e Sequências de Ensino Investigativo (SEI), sendo que uma SEI é uma proposta didática que tem por finalidade desenvolver conteúdos ou temas científicos. Este tema é investigado com o uso de diferentes atividades investigativas (por exemplo: laboratório aberto, demonstração investigativa, textos históricos, problemas e questões abertas, recursos tecnológicos). Em qualquer dos casos, a diretriz principal de uma atividade investigativa é o cuidado do(a) professor(a) com o grau de liberdade intelectual dado ao aluno e com a elaboração do problema. Estes dois itens são bastante importantes, pois é o problema proposto que irá desencadear o raciocínio dos alunos e sem liberdade intelectual eles não terão coragem de expor seus pensamentos, seus raciocínios e suas argumentações.

Em nossas reuniões, quando estávamos elaborando e testando nossas SEI, discutimos bastante um ponto que parece insignificante: se o 'investigativo' concordaria com 'sequência' - sequência de ensino investigativa - ou com 'ensino' - sequência de ensino investigativo. Essa querela só foi resolvida quando assistimos algumas aulas onde estavam sendo aplicadas nossas atividades investigativas por professores diretivos: as aulas não eram investigativas!!!!! Ficou claro para nós que um ensino investigativo vai muito além das atividades investigativas escritas para os alunos, estas são necessárias, mas não suficientes.

Uma segunda inferência necessária foi caracterizar melhor o que é 'grau de liberdade intelectual dado aos alunos' em cada uma das principais atividades de ensino de Ciências. Nos cursos de formação, nas discussões dos artigos teóricos, os professores defendiam a argumentação dos alunos em suas aulas e concordavam com a importância desta tarefa: criar condições em sala de aula para os alunos poderem participar sem medo de errar, isto é dar liberdade intelectual para os alunos. Entretanto, principalmente nas aulas do ensino médio, não era isso que acontecia. Se os professores tinham clara a necessidade da participação dos alunos na construção do conhecimento, uma vez que é com o uso de uma linguagem argumentativa que os fatos são transformados em evidência (Latour, \& Woolgar, 1997; Lemke, 1998a, 1998b, 2000; Jiménez-Aleixandre, 2005), não era isso que encontrávamos em sala de aula. Quando existiam possibilidades de ocorrência de situações argumentativas, na grande maioria das vezes, isto decorria somente na fala do professor, isto é, o professor fazia questões, muitas vezes questões interessantes, mas não esperava as respostas dos alunos. Em outras palavras, o professor não dava liberdade intelectual para os alunos pensarem e responderem as questões, ele mesmo respondia em continuação à exposição do conteúdo.

Esses dois conceitos - liberdade intelectual e elaboração de problemas - são essenciais para o professor criar condições em sala de aula para os alunos interagirem com o material e construírem seus conhecimentos em uma situação de ensino por investigação. Passamos então a caracteriza-los. 


\section{$1^{\circ}$ Conceito - Liberdade Intelectual Oferecida pelos Professores a seus Alunos}

Iniciamos o estudo sobre os graus de liberdade intelectual oferecido pelos professores a seus alunos com um texto de Pella (1969), no qual o autor estudava a liberdade intelectual que os materiais escritos para as aulas de laboratório de ciências nas 'high school' americanos ofereciam aos alunos. O autor elaborou uma tabela na qual associava as atividades possíveis de professores e de seus alunos quando cada tipo de instrução escrita era proposta à uma classificação destas atividades por seus graus de liberdade intelectual.

Mais recentemente, Borges (2004), propondo ensino investigativo em atividades de laboratório para a escola média, analisa a estrutura das aulas não por meio de níveis de liberdade intelectual dos alunos, mas de níveis de investigação. A partir desses dois artigos, organizamos quadros com a finalidade de caracterizar os modelos metodológicos passíveis de serem postos em execução em cada uma das atividades didáticas mais utilizadas no ensino de Ciências (laboratório, problemas de lápis e papel, textos históricos) mostrando o grau de liberdade intelectual que o professor proporciona para seus alunos em cada um dos modelos. Iniciamos a apresentação e discussão pela figura 1, que mostra os graus de liberdade oferecido aos alunos pelo professor em atividades experimentais.

\begin{tabular}{|l|c|c|c|c|c|}
\hline & Grau 1 & Grau 2 & Grau 3 & Grau 4 & Grau 5 \\
\hline Problema & $\mathrm{P}$ & $\mathrm{P}$ & $\mathrm{P}$ & $\mathrm{P}$ & $\mathrm{A}$ \\
\hline Hipóteses & $\mathrm{P}$ & $\mathrm{P} / \mathrm{A}$ & $\mathrm{P} / \mathrm{A}$ & $\mathrm{A}$ & $\mathrm{A}$ \\
\hline Plano de trabalho & $\mathrm{P}$ & $\mathrm{P} / \mathrm{A}$ & $\mathrm{A} / \mathrm{P}$ & $\mathrm{A}$ & $\mathrm{A}$ \\
\hline Obtenção de dados & $\mathrm{A}$ & $\mathrm{A}$ & $\mathrm{A}$ & $\mathrm{A}$ & $\mathrm{A}$ \\
\hline Conclusões & $\mathrm{P}$ & $\mathrm{A} / \mathrm{P} /$ Classe & $\mathrm{A} / \mathrm{P} /$ Classe & $\mathrm{A} / \mathrm{P} /$ Classe & $\mathrm{A} / \mathrm{P} /$ Classe \\
\hline
\end{tabular}

Figura 1. Graus de liberdade de professor (P) e alunos (A) em atividades experimentais (Carvalho, Ricardo, Sasseron, Abib, \& Pietrocola, 2010, p. 55)

A primeira coluna representa o modelo de ensino diretivo, no qual, na aula de laboratório, o professor apresenta o problema e as hipóteses, quase sempre por meio do referencial teórico, e mostra todos os passos do plano de trabalho, restando aos alunos somente acatar o receituário proposto. Por esse motivo, essas aulas são popularmente chamadas de 'receitas de cozinha'. Como os alunos têm que comprovar a teoria, as conclusões também já são conhecidas a priori. Tendo o conhecimento das conclusões e, portanto, de onde devem chegar a partir dos dados obtidos caso necessário, os alunos tendem a modificar seus dados originais para não errar frente ao professor. Essa coluna representa o grau 1 de liberdade intelectual e, infelizmente, caracteriza uma situação de ensino em que, além do conteúdo específico, os alunos podem aprender a não acreditar nos próprios dados.

A segunda coluna representa ainda um ensino diretivo, mas com um professor 
mais aberto e participativo. Nesta situação, apesar de as hipóteses e o plano de trabalho serem apresentados pelo professor, eles são discutidos com os alunos. Assim, é possível haver questões para que os alunos pensem porque fazer o que está sendo proposto, mas ainda é a resposta do professor que orienta o trabalho. Esse é o grau 2 de liberdade intelectual.

A terceira e a quarta colunas representam um ensino por investigação. Na terceira coluna, grau 3 de liberdade intelectual, o professor propõe o problema e as hipóteses são discutidas com os alunos, mas são estes que buscam como fazer a experiência, sob a supervisão do professor, que retomará a discussão com os alunos quando da discussão das conclusões. Diferentemente dos graus 1 e 2, quando o aluno procurava entender o raciocínio do professor, nos graus 3 e 4 é o aluno que está com a parte ativa do raciocínio intelectual. Um grupo pode errar, mas poderá ser o grupo que mais vai aprender, pois os alunos deste grupo terão de refazer o raciocínio buscando onde cometeram o engano.

A quarta coluna, grau 4 de liberdade, representa uma classe mais madura, já acostumada com o ensino por investigação, na qual os alunos estão acostumados a trabalhar em grupo e a tomar decisões para resolver os problemas. Entretanto, o papel do professor continua muito importante, uma vez que é ele quem propõe o problema a ser resolvido, discute algum aspecto com o grupo que solicitar e, no final, discute as conclusões. O problema deve estar relacionado ao contexto teórico estudado e as conclusões devem levar a uma visão mais profunda da teoria.

O grau 5, no qual o problema é escolhido e proposto pelo aluno ou grupo de alunos, é muito raro nos cursos fundamentais e médios. Encontramos, muito raramente, esses casos em Feiras de Ciências.

Além da atividade de laboratório, analisamos duas outras atividades didáticas importantes no ensino das Ciências: a resolução de problemas de lápis e papel e a aula na qual se introduz textos de História das Ciências para os alunos lerem e analisarem.

As figuras 2 e 3, que representam essas atividades, foram elaboradas a partir da discussão feita por Paiva (2015) em sua tese de doutorado.

A figura 2 procura mostrar a liberdade intelectual em uma das atividades mais frequentes no ensino de Ciências, em particular nos ensinos de Física e Química: as aulas de resolução de problemas. Nessas disciplinas, a avaliação dos alunos é feita quase que exclusivamente pela resolução de problemas.

\begin{tabular}{|l|c|c|c|c|c|}
\hline & Grau1 & Grau 2 & Grau 3 & Grau 4 & Grau 5 \\
\hline Problema & $\mathrm{P}$ & $\mathrm{P}$ & $\mathrm{P}$ & $\mathrm{P}$ & $\mathrm{A}$ \\
\hline Hipóteses & $\mathrm{P}$ & $\mathrm{P} / \mathrm{A}$ & $\mathrm{A} / \mathrm{P}$ & $\mathrm{A}$ & $\mathrm{A}$ \\
\hline Resolução do problema & $\mathrm{A}$ & $\mathrm{A}$ & $\mathrm{A}$ & $\mathrm{A}$ & $\mathrm{A}$ \\
\hline Análise dos resultados & $\begin{array}{l}\text { (quando } \\
\text { existe) P }\end{array}$ & $\begin{array}{l}\text { P/A/ } \\
\text { Classe }\end{array}$ & $\begin{array}{l}\text { P/A/ } \\
\text { Classe }\end{array}$ & $\begin{array}{l}\text { P/A/ } \\
\text { Classe }\end{array}$ & $\begin{array}{l}\text { P/A/ } \\
\text { Classe }\end{array}$ \\
\hline
\end{tabular}

Figura 2. Graus de liberdade de professor (P) e alunos (A) em aulas de resolução de problemas 
A análise desta figura é bastante semelhante à da figura 1. O grau 1 representa uma metodologia de ensino diretiva e um professor que resolve intelectualmente todo o problema deixando somente a resolução matemática para os alunos. Nessas aulas, é comum encontrarmos questões feitas pelos alunos do tipo "não entendi nada que o senhor explicou, pode explicar novamente?" e o professor explica com as mesmas ou com outras palavras. É importante que os alunos entendam, pois essa resolução será a mesma para outros problemas, ou melhor, outros exercícios. Então, os alunos devem decorar o raciocínio exposto pelo professor para poder repeti-lo em exercícios semelhantes. O grau 2 representa um ensino também diretivo, mas com um aluno um pouco mais participativo.

Os graus 3 e 4 caracterizam situações em que os alunos pensam, tomam decisões, discutem com seus colegas e a eles cabe chamar ou não a participação do professor. $\mathrm{O}$ certo ou o errado será discutido, agora com o professor, na etapa de análise dos resultados, quando então os possíveis raciocínios elaborados pelos estudantes serão comparados. Uma aula nesses dois graus de liberdade corresponde a uma metodologia investigativa. Também é muito difícil encontrarmos o grau 5 no ensino fundamental e médio.

A terceira atividade didática aqui analisada é a aula em que o professor apresenta um texto de História das Ciências. A introdução desses não é muito utilizada no ensino tradicional, apesar de encontrarmos textos históricos em alguns livros. Entretanto, ela é importantíssima em um curso cujos objetivos ultrapassam o ensino de conceitos, leis e teorias e em que se pretende alcançar o entendimento da construção do próprio conhecimento científico. Estas atividades de introdução de textos históricos no ensino, principalmente no nível médio, podem ser de grande valia para alcançar os objetivos epistêmicos e sociais da construção do conhecimento conceitual.

Apresentamos também aqui cinco graus de liberdade professor/aluno para descrever as possíveis ações intelectuais existentes nesse tipo de aula e caracterizar cinco dessas ações: a escolha do texto; a problematização, que são as questões que o professor faz para dirigir o olhar dos alunos durante a leitura; a própria leitura; a análise do texto e as conclusões (Figura 3).

\begin{tabular}{|l|c|c|c|c|c|}
\hline & Grau 1 & Grau 2 & Grau 3 & Grau 4 & Grau 5 \\
\hline Escolha do texto & $\mathrm{P}$ & $\mathrm{P}$ & $\mathrm{P}$ & $\mathrm{P}$ & $\mathrm{A}$ \\
\hline Problematização & $\mathrm{P}$ & $\mathrm{P} / \mathrm{A}$ & $\mathrm{A} / \mathrm{P}$ & $\mathrm{A}$ & $\mathrm{A}$ \\
\hline Leitura do Texto & $\mathrm{A}$ & $\mathrm{A}$ & $\mathrm{A}$ & $\mathrm{A}$ & $\mathrm{A}$ \\
\hline Análise do Texto & $\mathrm{P}$ & $\mathrm{A}$ & $\mathrm{A}$ & $\mathrm{A}$ & $\mathrm{A}$ \\
\hline Conclusões & $\mathrm{P}$ & $\mathrm{P}$ & $\mathrm{A} / \mathrm{P} /$ Classe & A/P/Classe & A/P/Classe \\
\hline
\end{tabular}

Figura 3. Graus de liberdade de professor (P) e alunos (A) em situações de discussão de textos históricos 
A análise da figura 3 é bastante similar à das anteriores. Os níveis 1 e 2 representam o ensino diretivo, sendo o professor do nível 2 mais aberto, uma vez que deixa as análises do texto serem feitas pelos alunos. Os níveis 3 e 4 representam um ensino investigativo sendo que no nível 3 o professor ainda dirige a problematização do texto, mesmo tendo a participação dos alunos. Essas problematizações são difíceis, pois são organizadas justamente para alcançar as visões epistemológicas e sociais da construção do conhecimento científico. Essa ação pode, aos poucos, ser deixada para os estudantes, pois sempre o professor pode voltar a esses pontos quando da discussão das conclusões.

\section{$2^{\circ}$ Conceito - 0 que é um bom problema?}

No início deste texto, propusemos que a diretriz principal de uma atividade investigativa é o cuidado do professor com o grau de liberdade intelectual dado ao aluno e com a elaboração do problema.

É necessário diferenciar o 'problema' proposto para os alunos resolverem nas aulas de laboratório, nos problemas abertos de lápis e papel, e mesmo nas questões propostas em outras atividades como, por exemplo, a que envolve História das Ciências de questões problematizadoras, muitas vezes propostas no início das sequências investigativas para dar um sentido social ao ensino.

Nas aulas de Ciências, do ensino Fundamental I ao ensino Médio, a existência de problemas abertos (nível 3 e 4 de liberdade intelectual) aponta para uma atividade inovadora, principalmente no ensino das atividades experimentais e na resolução de problemas de lápis e papel.

O problema se torna importante em atividades experimentais introdutoras de conceitos ou sistematizadoras de dados que levarão a leis quando procura relações entre outros conceitos já aprendidos, introduz nova proposta teórica e muitas outras estruturas científicas que devem ser postas na aprendizagem das Ciências.

Na resolução de problemas de lápis e papel, os alunos devem aprender a encontrar quais são as variáveis que interferem na resolução, diferentemente de um problema tradicional, ou melhor, um exercício, quando os alunos nem prestam atenção, pois estão acostumados a utilizar todos os dados oferecidos pelo professor. Outro fator importante que aparece nessas resoluções é um aspecto difícil no desenvolvimento científico: a introdução e o manejo da linguagem matemática para expressar os fenômenos da natureza.

Um bom problema é aquele que:

- dá condições para os alunos resolverem e explicarem o fenômeno envolvido no mesmo;

- dá condições para que as hipóteses levantadas pelos alunos levem a determinar as variáveis do mesmo; 
- dá condições para os alunos relacionarem o que aprenderam com o mundo em que vivem;

- dá condições para que os conhecimentos aprendidos sejam utilizados em outras disciplinas do conteúdo escolar;

- quando o conteúdo do problema está relacionado com os conceitos espontâneos dos alunos (Driver, Guesne, \& Tiberghien, 1985), esses devem aparecer como hipóteses dos mesmos.

Por outro lado, nas aulas experimentais um bom problema é aquele que dá condições para que os alunos:

- passem das ações manipulativas às ações intelectuais (elaboração e teste de hipóteses, raciocínio proporcional, construção da linguagem científica);

- construam explicações causais e legais (os conceitos e as leis).

\section{Retomando as pesquisas desenvolvidas no Grupo do LaPEF para discutir a relação entre ensino/aprendizagem/formação de professores}

Nas últimas décadas, nos propusemos a estudar a aprendizagem dos alunos ao participar das atividades e das sequências de ensino investigativo. Visando como meta final a formação de professores, tínhamos de saber 'o que' os alunos aprendem e 'como' aprendem. As pesquisas desenvolvidas trouxeram os dados empíricos que vieram a sustentar nossos referenciais teóricos. Esses referenciais, que utilizamos para elaborar as atividades investigativas e a metodologia de ensino, estão baseados nos trabalhos de Piaget e colaboradores em relação à psicogênese do conhecimento científico, isto é, a como o ser humano constrói o conhecimento e quais as principais estruturas desse pensamento; e nos trabalhos de Vigotsky, que mostram a importância do outro nessa construção e a importância da linguagem no desenvolvimento intelectual do aluno. Nos inúmeros trabalhos dos pesquisadores em ensino de Ciências desenvolvidos nessas últimas décadas, utilizamos também o livro de Latour e Woolgar (1995) que descreve o fazer científico em um laboratório; os trabalhos de Lemke (1998a) sobre a linguagem nas Ciências; os de Driver, Newton \& Osborne (1999) e Jiménez-Alexandre (2005) sobre a argumentação em sala de aula; os de Kelly (2008) sobre as ações epistêmicas; os de Sasseron e Carvalho (2008) sobre a alfabetização científica; e os de Carvalho e Gil-Perez (1993) sobre metodologia de ensino investigativa, além de inúmeros outros autores que têm publicado nas revistas da área.

O nosso Programa de Pesquisa, tanto para o Fundamental I como para o Ensino Médio, abrangia três fases:

1. aplicação das atividades ou das sequências de ensino investigativo (SEI) na Escola 
de Aplicação da Faculdade de Educação da USP ou em uma escola em que conhecíamos o professor e que permitia a gravação das aulas;

2. aplicação das atividades ou das SEI por vários outros professores nossos conhecidos, de tal forma que pudéssemos receber o feedback das aulas;

3. aplicação das atividades ou das SEI em escolas da comunidade.

Todas as investigações da fase 1 seguiram a mesma metodologia de pesquisa, que pode ser classificada, segundo Richardson (2009), como qualitativa, pois:

"descreve a complexidade de determinado problema analisando a interação de certas variáveis e procura descobrir e classificar a relação entre variáveis além de investigar a semelhança de causalidade entre fenômenos." (p. 70).

No contexto do grande guarda-chuva das pesquisas qualitativas, optamos pelo Estudo de Casos, pois, como mostra Yin (2010),

“os Estudos de Casos partem do princípio de que as questões 'como' e 'o que’ são enfocadas (...) é preferido no exame dos eventos contemporâneos quando os comportamentos relevantes não podem ser manipulados (...) conta com pelo menos duas fontes de evidências: observação direta e entrevistas das pessoas envolvidas nos eventos." (p. 32).

Os pontos indicados por Yin para Estudos de Caso se ajustaram perfeitamente aos nossos objetivos, uma vez que procuramos conhecer 'o que' os alunos aprendem (conteúdo, argumentação, escrita), 'como aprendem' (por exemplo, quais questões do professor podem provocar argumentação dos alunos ou qual metodologia é proposta pelo professor para a interpretação de um texto histórico). Nossas fontes de dados foram justamente a técnica de coleta de dados por vídeos de todas as aulas das atividades investigadas e entrevistas ou trabalhos dos alunos para, de maneira triangular, procurar a convergência entre os resultados. Todas as gravações foram realizadas em escolas com a autorização, por escrito, dos professores e dos alunos ou seus pais quando esses eram menores de idade.

\section{Pesquisas sobre ensino e aprendizagem a partir de atividades investigativas experimentais no Ensino Fundamental I}

Para iniciarmos as pesquisas sobre o ensino e aprendizagem de Ciências no Fundamental I, foi preciso primeiramente construir os problemas, definir o planejamento geral das aulas e o papel do professor.

Os problemas. A atividade escolhida para as pesquisas no ensino Fundamental I foi o problema experimental relacionado ao conteúdo de Física que chamamos de Conhecimento Físico (Carvalho, Barros, Gonçalves, Rey, \& Vannucchi, 1996). Nossos problemas experimentais estavam no nível 4 de liberdade intelectual dado ao aluno, obedecendo as condições definidas anteriormente no item 'o que é um bom problema'.

A metodologia de ensino dessas aulas experimentais foi planejada em cinco 
etapas:

- distribuição do material experimental para os alunos reunidos em grupos pequenos (4 a 5 alunos). O professor propõe o problema e verifica se todos os grupos entenderam a questão proposta. Os alunos iniciam, nos grupos, os diálogos entre os alunos com a finalidade de resolver o problema com o material experimental dado;

- tendo os alunos resolvido o problema experimentalmente, o professor recolhe o material experimental, dissolve os grupos pequenos formando um grande círculo de tal forma que todos os alunos se vejam. A pergunta fundamental do professor nesta etapa é: "como vocês fizeram para resolver o problema?". Procurando responder essa questão, os alunos tomam consciência do que fizeram e, com suas respostas, vão passando da ação manipulativa à ação intelectual (Piaget, 1977; 1978). É importante criar oportunidades para que todos os alunos falem e procurar aumentar a interação com aqueles que raramente participam;

- ainda no grupo grande, depois de os alunos responderem como fizeram para resolver o problema, a outra pergunta chave é: "por que deu certo?". Essa questão deve levar os alunos a buscar a causalidade física (Piaget, \& Garcia, 1984), iniciando a construção dos conceitos. É bastante provável que, no início da interação entre alunos e entre alunos e professor, este precise auxiliar na construção do conceito, não expondo o mesmo, mas com perguntas que levem os alunos a argumentar;

- na sequência, a pergunta principal para os alunos é: “aonde vocês vêm isso em nosso dia a dia?". Ao procurar responder essa questão, os alunos buscam aplicar em seu cotidiano o conceito ou as relações que acabam de construir;

- no final, é tempo de escrever. O professor deve solicitar aos alunos que escrevam e desenhem o que aprenderam. Essa etapa é individual, de tal modo que os alunos possam se expressar livremente por meio da escrita e do desenho.

A partir deste planejamento, os alunos participam de interações aluno/aluno nos grupos pequenos, aluno/aluno/professor no grupo grande e têm participação individual na escrita. Orientamos os professores nos manejos e nas principais questões, deixando sob sua responsabilidade as outras questões.

Pesquisamos a aprendizagem dos alunos relacionando-a com a maneira como o ensino era realizado em sete dissertações de mestrado: Gonçalves (1991), Rey (2000), Oliveira (2003), Sedano (2005), Sasseron (2005), Locatelli, (2006) e Padilha (2008).

A primeira das dissertações (Gonçalves, 1991), nos mostrou que os alunos do Fundamental I eram capazes de resolver problemas de conhecimento físico e que em cada uma das etapas eles mostravam raciocínios diferentes: ao resolverem problemas em grupo, eles expunham seus conhecimentos cotidianos para levantar hipóteses de como 
resolver o problema; na etapa do 'como', eles realmente falavam sobre como resolveram o problema quando lentamente tomavam consciência de suas ações, como mostrava a teoria (Piaget 1977) e na fase do 'porque', quando eles procuravam uma explicação para o fenômeno. A maior parte destas explicações era legal ${ }^{1}$, isto é mostravam as relações entre as variáveis, mas sempre existiam alunos que chegavam à explicação causal, isto é, conseguiam construir o conceito físico (Piaget, \& Garcia, 1973).

Como os dados de Gonçalves (1991) foram coletados na Escola de Aplicação da FEUSP com quatro atividades, decidimos replicar a investigação com professoras de outras escolas públicas e com outros problemas experimentais. Construímos mais onze problemas experimentais e Rey (2000) testou esses novos problemas de conhecimento físico em escolas oficiais, obtendo em sua dissertação resultados muito semelhantes aos de Gonçalves: os alunos conseguiam resolver os problemas, durante a resolução eles levantavam hipóteses e relacionavam as variáveis e chegavam às explicações legais. Os dados nos mostraram que, diferentemente da expressão oral, a escrita dos alunos menos favorecidos economicamente apresentava poucas palavras e muitos erros de português, indicando mais a dificuldade da alfabetização do que da compreensão do fenômeno científico.

Todas as aulas foram gravadas e os vídeos dessas aulas podem ser obtidos no seguinte endereço: www.youtube/lapef/videos.

Mas o que era uma escrita pobre ou rica em termos de escrita científica? Esse foi o problema de Oliveira (2003), que analisou os trabalhos escritos de 10 alunos em três atividades de conhecimento físico diferentes. Apesar das diferenças entre o tamanho dos trabalhos, acertos de gramática e grafia, a grande maioria dos textos analisados apresentava semelhanças nos aspectos científicos: ordem cronológica similar à que ocorreu durante a atividade, mostrando o entendimento do problema e sua resolução; uso de verbos de ação na primeira pessoa do plural, mostrando a importância do trabalho em equipe; uma incidência muito maior de explicações legais do que causais, mostrando a dificuldades da construção da causalidade física.

Procurando outros aspectos da enculturação científica, Sedano (2005) estudou a construção da autonomia moral dos alunos durante o trabalho em pequenos grupos propondo o seguinte problema: "Quais são as atitudes dos alunos nos grupos de trabalho das aulas de ciências que usam atividades de Conhecimento Físico?". Usando as gravações já realizadas, foram analisados os dados de quatro grupos de trabalho de duas escolas públicas, sendo encontrados episódios de ensino que apontavam para as atitudes de interação, participação, cooperação, descentração e também atitudes de convivência com valores (opiniões ou atitudes) antagônicos e conflitantes. Neste estudo, também foi possível mostrar a diversidade de ações, pautadas em atitudes, que o aluno tem a

1 Piaget e Garcia (1973) usaram os termos 'legal' e 'causal' para diferenciar os dois tipos de explicações dadas pelas crianças e adolescentes. O termo legal é usado quando a explicação é descritiva, mostrando as relações entre as variáveis, por exemplo, a explicação do aluno é 'quanto mais água no tubo, mais longe vai a água quando sai do cano. Por outro lado, o termo causal é usado quando o aluno procura uma palavra nova para descrever o fenômeno como, por exemplo, em 'a água vai mais longe por causa da pressão'. 
oportunidade de vivenciar e atuar quando participa de uma proposta metodológica que dê espaço para isso.

Sasseron (2005) procurou detectar influências culturais na construção do conhecimento físico nas atividades investigativas propostas. $\mathrm{O}$ objetivo era identificar quando e como a cultura do aluno pode influenciar seu trabalho na resolução de um problema de Conhecimento Físico. As atividades foram aplicadas por uma professora indígena para os alunos da Escola Estadual Indígena Tupi Guarani Ywy Pyaú, de Peruíbe, estado de São Paulo. A conclusão foi a existência de influências culturais advindas das duas sociedades envolvidas nas aulas de Ciências em termos de interação entre aluno/ aluno e professora/alunos, mas pouca influência em relação ao pensamento científico.

Procurando nos aprofundar na estrutura da argumentação dos alunos, Locatelli (2006) analisou as aulas gravadas pelos profissionais, que serviram para a elaboração dos quinze vídeos, pois essas gravações tinham uma qualidade de imagem e de som muito superior à nossas, principalmente no trabalho dos alunos em grupo. Para subsidiar a análise dos dados, foram usados os referenciais teóricos de Lawson (2000a, 2000b, 2001), que mostra como os humanos constroem o conhecimento científico, e o trabalho de Inhelder e Piaget (1976), no qual eles estudaram o desenvolvimento lógico de crianças e adolescentes. Locatelli mostrou que, no discurso dos alunos, é possível vislumbrar importantes aspectos da estrutura de pensamento da cultura científica, entre eles, o levantamento de hipóteses, o início do raciocínio hipotético-dedutivo (se, então, portanto) e a construção das relações compensatórias entre as variáveis.

O último trabalho que desenvolvemos sobre o ensino e a aprendizagem das Atividades de Conhecimento Físico foi a pesquisa de Padilha (2008), também realizada na Escola de Aplicação, que procurou verificar como as linguagens verbal e gestual se articulam para dar sentido ao vocabulário utilizado no momento da argumentação. Através da análise integrada do modo verbal e gestual de comunicação, percebemos que a falta da palavra adequada não impossibilitou a comunicação e, em convergência com os trabalhos relacionados à Semiótica Social, vimos que o modo verbal muitas vezes não é suficiente para que possamos compreender o que o aluno quer dizer. No ato da comunicação do aluno, é importante que notemos a diferença entre a ideia que o aluno quer transmitir e os significados atribuídos a determinadas palavras utilizadas no ato da comunicação verbal. Houve momentos em que não só os gestos, mas também as expressões faciais, a entonação de voz e características apresentadas no ato da comunicação ajudaram a compreender o que o aluno queria dizer.

Além das conclusões parciais de cada uma das dissertações, o que podemos tirar do conjunto destas pesquisas é que: $s e$ os professores ao aplicarem em suas salas de aula as Atividades de Conhecimento Físico propondo o problema para os alunos, deixandoos interagirem em pequenos grupos, depois no grupo grande, perguntar "como?" $\boldsymbol{e}$ dando liberdade intelectual para eles falarem sem repressão, e depois perguntar "por que?" então os alunos argumentarão, levantarão suas hipótese, explicarão o fenômeno, apresentarão os raciocínios hipotético dedutivo, construindo relações compensatórias 
entre as variáveis, escreverão, construirão autonomia moral e portanto eles entrarão sendo introduzidos na cultura científica, aprendendo a falar e a escrever ciências.

Este é um conhecimento já estabelecido, pois essas atividades têm sido replicadas em muitas situações diferenciadas de ensino com resultados semelhantes aos nossos. Entretanto, desde as primeiras pesquisas, os dados nos mostraram a grande importância do papel do professor, pois não é fácil manter um ambiente não coercitivo em sala de aula, onde os alunos possam apresentar seus argumentos sem medo, estejam estes corretos ou não. De outro lado, não queríamos ficar pesquisando somente as atividades de conhecimento físico, queríamos saber como os alunos aprendem em outras atividades das Sequências de Ensino Investigativo (SEI) para o ensino de Ciências do Fundamental I que organizamos (Carvalho, et.al. 2011).

Assim, os trabalhos do grupo se dividiram: tivemos três trabalhos em formação de professores nas atividades de Conhecimento Físico: a tese de Gonçalves (1997) e as dissertações de Tinoco (2000) e Abrahão (2004); e três teses estudando outras atividades das SEI: Sasseron (2008), Oliveira (2009) e Sedano (2010). Na sequência, discutimos algumas ideias relevantes desses trabalhos.

\section{Pesquisas sobre formação de professores para o ensino de atividades de conhecimento físico}

Na pesquisa de Gonçalves (1997), procuramos analisar as contribuições de um curso de formação (30h) para o processo de compreensão das novas ideias que estávamos propondo, bem como estudar como as professoras as implementaram na sala de aula. Portanto, organizamos o curso com o objetivo explícito de fazer com que os participantes tentassem aplicar as atividades. $\mathrm{O}$ êxito nessa tentativa dependeria da compreensão crítica dos professores com respeito às ideias do curso. Todas as aulas do curso de formação, assim como as aulas das professoras que quiseram testar as atividades em suas próprias escolas, foram gravadas e analisadas.

As principais ideias da nova proposta de ensino do curso foram analisadas a partir de três conceitos: familiaridade, reconhecimento e fidelidade (Gonçalves, 1997).

A familiaridade se relaciona aos princípios básicos da concepção educacional da proposta. Por exemplo, nosso caso era uma proposta de ensino investigativo, baseada em um referencial construtivista segundo o qual o aluno era o construtor de sua aprendizagem, e na qual todo o conhecimento deveria ser elaborado a partir de problemas experimentais, proporcionando liberdade intelectual para os alunos. Sendo assim, em todos os cursos deveriam existir espaços para discutir as ideias, as crenças e a visão sobre o ensino e a aprendizagem do conteúdo específico que estava sendo tratado e que os professores elaboraram durante suas vidas profissionais e trouxeram para o curso. Com a categoria familiaridade, identificamos as ideias que podíamos reafirmar e aquelas sobre as quais era necessário conflitar explicitamente para oferecer aos professores os elementos de discriminação. As mudanças dos conceitos trazidos pelos professores e seus conceitos de ensino por investigação foram estudados por Tinocco (2000) em um 
curso de formação de 60 horas.

A categoria reconhecimento também está ligada aos conceitos básicos da proposta do curso, pois cada atividade programada, como vídeos, textos, artigos ou mesmo exposição, são interpretados pelos participantes, que os leem de sua maneira e os interpretam de acordo com seu interesse. Assim, cada professor realiza seu processo de leitura, refletindo sobre as próprias ideias e sobre sua prática, relacionando nossas ideias com as suas. O reconhecimento é, portanto, uma tomada de consciência pelo professor da diferença entre suas próprias ideias e as que o formador estava apresentando (Gonçalves, 1997; Tinocco 2000).

O reconhecimento precisa ser feito em relação a todas as ideias chaves do programa a ser apresentado. Por exemplo, em nosso curso, a ideia de "levar em conta o aluno na organização do ensino" era diferente da dos professores. Para os participantes, conhecer o aluno estava relacionado a conhecer as condições de vida dos estudantes, sua situação econômica e social, suas vivências e seu dia-a-dia. Entretanto, os muitos episódios registrados de reconhecimento, especialmente aqueles sobre a capacidade dos alunos, sobre o tipo de explicação que eles constroem e sobre o trabalho experimental em grupo indicam que a nossa ideia de "levar em conta o aluno" foi compreendida, ainda que os professores não tenham mudado suas concepções a esse respeito.

A categoria fidelidade está relacionada à máxima: "mesmo o que parece copiado, na realidade é deformado e recriado". Não esperávamos que os professores copiassem a proposta do curso em suas salas de aula, mas que as recriassem. A categoria fidelidade foi, na verdade, estudada a partir dos vídeos que os professores trouxeram de suas aulas nas quais a proposta do curso foi aplicada. Essa é uma atividade muito importante de ser planejada nos cursos de formação, pois fortalece a proposta de ensino, e tem o poder de gerar discussões que promovem a familiaridade e o reconhecimento e, portanto, a compreensão da proposta. Essa atividade formação - análise conjunta de vídeos de aulas dadas pelos professores - foi estudada também por Abrahão (2004).

Além das conclusões parciais de cada um dos trabalhos realizados, podemos tirar do conjunto destas pesquisas dois pontos importantes:

- estes três conceitos - familiaridade, reconhecimento e fidelidade - precisam ser observados pelo formador durante os cursos de formação. Quanto mais os professores/alunos se familiarizarem com as novas propostas e reconhecerem a diferença entre os novos conceitos e os antigos, com mais fidelidade eles as utilizarão em suas aulas;

- a análise conjunta dos vídeos de aulas dadas pelos professores em suas próprias classes é a atividade de formação que mais permitiu aos professores expressar suas ideias sobre ensino e ensino de ciências. Para isto, contribui o fato de, a partir das argumentações apresentadas, o formador poder tomar conhecimento do aprofundamento teórico necessário. Assim, para um curso de formação, essa atividade tem o mesmo potencial de uma atividade experimental investigativa 
para os alunos do Fundamental.

Esses trabalhos em formação continuada de professores em conjunto com os três doutorados que enfocavam o ensino e a aprendizagem das SEI que organizamos nos trouxeram segurança para testar nossas ideias de ensino por investigação de Ciências nas escolas oficiais e particulares.

\section{Pesquisas sobre Ensino, Aprendizagem e Formação de Professores em uma Escola Municipal: A generalização de nossos dados}

Com o financiamento do $\mathrm{CNPq}$, interagimos durante quatro anos com uma Escola Municipal de Ensino Fundamental (EMEF) da Grande São Paulo. Nossas SEI foram aplicadas e a escola deu autorização para que filmássemos uma delas durante um ano em uma de suas classes com o objetivo de obter dados para as pesquisas em ensino e aprendizagem. Em contrapartida, organizamos um processo de formação continuada para toda a equipe escolar com foco na aprendizagem da docência em geral e na docência de ciências em particular. Essa formação também foi gravada visando investigações em formação de professores.

Planejamos e desenvolvemos uma série de 'sequências formativas' que consistiam em dois fóruns, F1 e F2, que se realizavam a cada semana, uma vez na Escola a outra na Faculdade de Educação. No fórum F1, na escola, discutimos as atividades de ensino investigativo de ciências das SEI e suas bases científicas e epistemológicas. Estas mesmas atividades seriam aplicadas, durante a semana, por algumas das professoras em suas salas de aula do Ensino Fundamental. Esse fórum teve três objetivos: (i) focalizar o conteúdo conceitual das ciências que poderia ser ensinado através de atividades de ensino investigativas produzidas no LaPEF; (ii) propor uma metodologia de ensino que levasse em conta os conhecimentos produzidos pelas pesquisas na área de ensino de ciências; e (iii) apresentar e discutir os pressupostos epistemológicos que fundamentavam tanto as atividades de ensino como a metodologia proposta para esse ensino.

No fórum F2, tínhamos como ponto de partida a hipótese de que a prática reflexiva coletiva favorece a emergência de elementos teóricos e críticos, o que pode levar o professor a tomar consciência sobre o que fazer e por que fazer e, subsequentemente, pode gerar mudanças em suas práticas docentes. Deste modo, este fórum teve dois objetivos que se desenvolveram simultaneamente: (i) favorecer a tomada de consciência da relação teoria/prática, o que proporciona uma explicação para o fenômeno 'ensino e aprendizagem' de certos conteúdos e ações, propiciando generalizações para outros conteúdos e ações similares; e (ii) favorecer a ampliação do referencial teórico para outros conteúdos curriculares, sendo que esse objetivo se relaciona ao fato de, nos primeiros anos do ensino fundamental, a professora ser polivalente, não podendo o ensino de Ciências ficar fora do contexto do ensino de Matemática, Historia, Geografia e mesmo de Alfabetização. Assim providenciamos palestras e oficinas sobre o ensino dessas disciplinas.

O projeto teve repercussão na Escola, medido pelo interesse dos alunos e 
pais em uma feira de ciências (trabalho apresentado pelas professoras na FEUSP e ANPED em 2011); e também em todo o bairro. O diretor de outra EMEF solicitou que desenvolvêssemos trabalho semelhante em sua escola. Sua solicitação foi atendida a partir da condução de um projeto de formação de professores e criação de um bom ambiente de pesquisa, também com o apoio do CNPq, durante dois anos.

No IDEB (Índice de Desenvolvimento da Educação Básica) de 2011, ambas as escolas apresentaram um índice que seria esperado para duas edições a frente, revelando um grande avanço na formação esperada para os estudantes pelas agências oficiais. Ainda que muitos possam ser os motivos para este êxito, certamente nosso projeto contribuiu para isso, uma vez que esteve voltado para a formação dos professores no desenvolvimento de propostas didáticas que privilegiam a liberdade intelectual dos estudantes.

São inúmeros nossos dados de pesquisa. Estes sustentaram os trabalhos nas duas linhas de nosso Grupo: a formação de professores e o trabalho em sala de aula.

Tendo o foco a formação de professores, publicamos um capítulo de livro (Carvalho, 2010), um artigo (Briccia, \& Carvalho, 2016) e foi concluída uma tese de doutorado (Nascimento, 2012).

Nascimento (2012) mostrou, dentre outras conclusões, a importância do trabalho em equipe para o desenvolvimento das atividades em sala de aula. As reuniões com a coordenadora deram apoio às professoras, sendo que nessas reuniões houve muita troca de experiência entre as docentes. Esse fato foi fundamental para o êxito da mudança metodológica proposta pela formação.

Os trabalhos que estudaram o ensino em sala de aula tiveram a orientação da Dra. Sasseron. O primeiro, o mestrado de Afonso (2011), procurou analisar os indicadores de alfabetização científica (Sasseron, 2008) que os alunos alcançaram em uma das SEI aplicadas. Em duas aulas analisadas, Afonso encontrou os seguintes indicadores: explicação, levantamento de hipóteses, organização de informações, explicação, levantamento de hipótese, raciocínio proporcional, seriação e organização de informações, explicação, previsão e justificativa. Esses mesmos indicadores também estavam presentes nas aulas dessa mesma sequência de ensino investigativa quando ensinada na Escola de Aplicação.

A dissertação de mestrado de Freiberg (2015) estudou o papel da professora na negociação de sentidos entre seus alunos para a resolução de um dos problemas de uma das SEI. Esse mesmo problema foi também estudado por Bastos (2017) em sua tese de doutorado, quando a autora procurou responder a uma série de questões sobre os problemas na Abordagem Didática do Ensino por Investigação.

O último dos trabalhos realizados no contexto das Escolas Municipais sobre formação continuada para as professoras foi a tese de doutorado de Nascimento (2017), que pesquisou as práticas de sala de aula. Estudando as atividades de uma SEI, ela identificou diferentes operações realizadas pela professora e pelos estudantes para que estes se engajassem em processos simplificados do trabalho científico. Por exemplo, 
foi percebida uma forte relação entre a prática de fazer perguntas e outras como a argumentação, a análise e interpretação de dados, o uso de pensamento matemático ou a construção de explicações.

\section{Conclusões Muito Gerais das Pesquisa em Ensino, Aprendizagem e Formação de Professores no Fundamental I}

Dos trabalhos de pesquisa relatados que procuraram estudar o ensino e a aprendizagem em sala de aula de Ciências no ciclo Fundamental I, podemos sustentar que as atividades investigativas e as sequências de ensino investigativo abrangem objetivos de ensino conceituais, epistêmicos e sociais, além de conteúdos significativos para os estudantes, criando oportunidades para que estes se alfabetizem cientificamente vivenciando diferentes práticas similares às da comunidade científica.

As pesquisas em formação de professores para esse ciclo nos mostraram que é possível obter uma mudança de paradigma do ensino em sala de aula - do tradicional ao investigativo - sempre que as condições de formação também sejam investigativas, isto é, apresentem problemas de ensino e aprendizagem significativos para os professores utilizando, sempre que possível, suas próprias aulas como fonte para discussão. Além disto, é essencial que, nestas discussões, além da teoria e da prática do ensino por investigação, sejam oferecidas liberdade intelectual para os professores se expressarem e se posicionarem. Entretanto as pesquisas mostraram que, finda a formação, os professores buscam a coordenação e a discussão com seus pares para resolver os problemas que enfrentam no dia a dia, sendo essa busca de auxílio de seus pares muito importante para a confiança em continuar com a inovação.

\section{Pesquisas sobre Ensino, Aprendizagem e Formação de Professores no Grau Médio}

As pesquisas desenvolvidas no grau médio tiveram as mesmas bases teóricas e metodológicas de ensino e de pesquisa já explicitadas tanto para o desenvolvimento das atividades de ensino por investigação quanto para o desenvolvimento da pesquisa em sala de aula.

Entretanto, para o ensino nesse nível temos algumas variáveis a mais:

- o desenvolvimento histórico-epistemológico do conteúdo a ser ensinado. Esse conteúdo é muito extenso em termos históricos e epistemológicos indo de Galileu no século XVI (quando a Ciência era mais Filosofia, com quase nenhuma linguagem matemática) à Física Moderna e Contemporânea do século XX (quando o desenvolvimento matemático para a explicação de fenômenos científicos está muito além da compreensão dos alunos do ensino médio). Assim, além de introduzir um ensino libertário, em termos de dar aos alunos liberdade intelectual para pensar e construir seus conhecimentos, as SEI para o Ensino Médio devem abordar um largo período histórico, levando os alunos a entender 
várias mudanças de paradigmas, em termos de entendimento da natureza da ciência que está sendo ensinada (Física, Química ou Biologia), que aconteceram durante esses quatro séculos;

- as condições de trabalho do professor. Cada uma das disciplinas científicas tem poucas aulas semanais nas escolas oficiais, tendo o professor muitas classes com muitos alunos. Assim, o professor não tem condições sequer de conhecer bem seus alunos, o que dificulta muito a interação professor/aluno. No ensino das Ciências (Física, Química ou Biologia) para o Médio, não podemos trabalhar na formação de professores com uma escola como no nível Fundamental I, pois em cada escola oficial há um ou no máximo dois professores de cada uma das disciplinas. Temos então de trabalhar com uma Diretoria de Ensino e com professores que mal se conhecem.

- a elaboração das atividades investigativas. No grau médio, para o desenvolvimento do conteúdo, além de atividades de laboratório investigativo, é necessário planejar também atividades investigativas para as aulas nas quais serão discutidos os textos históricos, os sites de conteúdo e as resoluções de problemas. Além disso, para as atividades de laboratório, o material experimental é bem mais complexo, dificultando a proposição do problema.

Procurando superar todas essas variáveis o grupo do LaPEF elaborou as seguintes sequências investigativas visando dar sustentação às pesquisas de ensino e aprendizagem e formação de professores envolvendo conteúdos de Física na escola média:

- Três SEI sobre Calor e Temperatura (publicadas inicialmente em Carvalho et al. 1999 e atualizadas em Carvalho 2014) em que focalizamos a mudança do entendimento do calor como calórico para calor como transmissão de energia, e outros conteúdos de termologia e calorimetria.

- Duas SEI sobre o início da Física Contemporânea.

- Uma SEI sobre quantidade de movimento, sua conservação e as leis de Newton (Bellucco 2015).

\section{SEI sobre calor e temperatura e as pesquisas sobre Formação de Professores}

Tivemos oportunidade de participar do programa Pró-Ciência CAPES/FAPESP, organizando um curso de formação de professores com o objetivo geral de verificar a possibilidade de obter uma melhoria no aprendizado dos alunos sobre o conteúdo de Termologia e Calorimetria, nas condições normais de trabalho nas Escolas Públicas, a partir de uma mudança do ensino realizado por seus professores

A escolha do conteúdo se deu por já trabalharmos com esse tema em várias pesquisas: o doutorado de Teixeira (1993), que estudou a mudança conceitual e o 
desenvolvimento dos conceitos de calor e temperatura; o doutorado de Silva (1995), que estudou as trajetórias cognitivas de alunos no ensino da diferenciação dos conceitos de calor e temperatura; e o mestrado de Castro (1993), que investigou a aprendizagem dos alunos nos textos históricos. Para esta pesquisa, foram utilizados três textos retirados de Maggie (1935): uma carta de Fahrenheit escrita a um colega cientista relatando o aperfeiçoamento do termômetro; um fragmento de uma conferência de Joseph Black, que em 1760 sugere a necessidade de distinguir os conceitos de calor de temperatura; e um texto de Rumford no qual ele descreve sua experiência com os canhões e a impossibilidade de explicação de seus dados pela teoria do calórico. O texto de Fahrenheit mostra o intenso envolvimento de um pesquisador em seu trabalho de investigação e o uso de conhecimentos já produzidos e publicados. O texto de Black é um texto de reconstrução de ideias, pois também os alunos têm dificuldade de distinguir esses dois conceitos (calor e temperatura). O texto de Rumford reflete a dificuldade de análise de dados empíricos que estavam em desacordo com o modelo explicativo vigente.

O curso de formação para professores em serviço de uma Diretoria de Ensino da Grande São Paulo consistia em encontros semanais. Foram três anos de trabalho conjunto. Além de discussões dos textos teóricos, nosso trabalho se direcionou a procurar que os professores tomassem consciência do próprio ensino, de tal modo que as participações dos estudantes ficassem bem definidas para eles, planejando com cuidado essa mesma participação durante todas as aulas, procurando sempre deixar claro como e quando eles (os professores) davam liberdade para que os alunos refletissem sobre o que estavam aprendendo, estimulando assim a participação do aprendiz no seu próprio aprendizado. Todas as reuniões foram gravadas em áudio e todas as aulas de uma professora foram gravadas em vídeo.

A meta-cognição sobre o trabalho docente tomou uma direção bastante forte sobre a relação entre suas ações e seus questionamentos com a qualidade da participação dos estudantes em suas aulas. Tanto nas aulas de laboratório (de demonstração ou de investigação) como nas de questões e problemas abertos, leitura dos textos da história das ciências ou dos textos de apoio, e também na apresentação dos vídeos, a relação professor/alunos foi o foco de nossas discussões.

Em nossas discussões no LAPEF, procuramos favorecer que os professores, em suas aulas, apresentassem a Ciência (a Termologia e a Calorimetria) como um processo no qual o conhecimento científico é (em sala de aula) e foi (na História da Ciência) socialmente construído. Portanto o papel da argumentação entre os alunos foi bastante valorizado, e os professores planejaram e realizaram em suas classes muitas atividades em grupo para discutir questões. Discutimos as atividades dadas em sala de aula que proporcionaram aos alunos de nossos professores boas oportunidades de se envolver em práticas discursivas, socializando os jovens na argumentação científica. Os professores mostraram suas argumentações sobre as melhores condições de seu trabalho docente para que os alunos construíssem, a partir de sua linguagem cotidiana, uma linguagem científica (sendo que a linguagem científica nesse nível de ensino abrange também as 
linguagens argumentativa, gráfica e a matemática).

As experiências de laboratório, mesmo as de demonstração, foram planejadas para que os alunos expusessem suas ideias na busca de explicações para os fenômenos apresentados, testando seus modelos explicativos espontâneos e, auxiliados pelas argumentações aluno/aluno, alunos/professor, aluno/textos, construíssem seus modelos científicos.

Os professores construíram três Sequências de Ensino Investigativo que foram publicadas inicialmente em 1999 e reformuladas em 2014 (Carvalho et al. 1999, 2014).

Com os dados retirados das gravações dos encontros no LaPEF, foram realizadas duas dissertações de mestrado (Rodrigues, 2001 e Cilurzo, 2002), com os objetivos de analisar e avaliar o Projeto de Educação Continuada. Além disso, os dados das gravações de sala de aula foram analisados em uma tese de doutorado (Capecchi, 2004) e outra dissertação de mestrado (Carmo, 2006).

As conclusões dessas dissertações mostram que a parceria permitiu que os participantes se engajassem num diálogo franco e aberto para enfrentar os sérios desafios de uma sala de aula na escola pública e proporcionou feedbacks rápidos aos participantes.

As condições especialmente criadas com o trabalho em equipe, semana-asemana, geraram oportunidades para que os professores olhassem retrospectivamente para os problemas e dificuldades do dia-a-dia da sala de aula. Os diálogos mostravam os descompassos da implementação do projeto, marcados pela greve de professores ou de outras interrupções, pela necessidade de avaliação, pela frequência irregular dos alunos e pela dificuldade de sistematização dos dados. Os professores compartilharam suas dúvidas muito confortavelmente. Eles vivenciaram alguns momentos problemáticos, de desânimo, mas não apostaram no conflito desestabilizante; ao contrário, converteram aqueles momentos difíceis e duvidosos em ocasiões de fortalecimento. Assim, as discussões ofereceram espaços para os 'desabafos', reduziram a ansiedade, revigoraram as partes.

A prática descompassada do projeto preocupava muito os professores. Entretanto, o desejo de uniformização não se concretizou - e nem poderia, pois as ações e práticas dos professores eram altamente dependentes do contexto e das características individuais e profissionais de cada um.

Outra preocupação emergente nos diálogos foi a avaliação. Era necessário ter uma tolerância considerável à diversidade dos alunos. Ao mesmo tempo, a avaliação cobrava um aprendizado dos estudantes, interferia no trabalho pessoal e no projeto em si. Ao considerar a avaliação dos alunos como preocupação central durante a construção do projeto, a análise das reuniões mostrou que dos professores se exigiam hábitos de trabalho diferentes do comum: contínua preocupação com o entendimento do conteúdo planejado e averiguações da compreensão no momento oportuno da aprendizagem. Essas ações trouxeram retornos imediatos, pois compreender o que o aluno entende exige uma profunda compreensão da matéria que está sendo ensinada e do processo de 
aprendizagem.

Cilurzo (2002) mostrou que a avaliação conduziu diretamente à reflexão e esta à avaliação. Ao olharem coletiva e retrospectivamente para o seu ensino e para a aprendizagem que estava ocorrendo, os professores recapturaram e reestruturaram suas ações e aprenderam com a experiência. As reuniões semanais geraram planejamento ação - reflexão, nem sempre nessa ordem (Rodrigues 2001), mas todas relacionadas ao contexto do professor e mediadas pela constante avaliação e posterior reconstrução.

Outros pontos de reflexão foram: as dificuldades dos alunos, seu desinteresse, a frequência irregular e o apuro dos estudantes em passar da oralidade para a escrita. Os diálogos relacionados a esses pontos revelaram que os professores estavam, acima de tudo, preocupados com o êxito de seus alunos. Importava-lhes avançar o cronograma traçado, mas importava-lhes principalmente avaliar que o conteúdo ensinado fora assimilado pelos alunos, ainda que isso provocasse um atraso no cronograma de atividades.

Todos os professores participantes foram solicitados, nos espaços de HTPCs (Horas de Trabalho Pedagógico Coletivo), a falar da pesquisa que estavam realizando. Quando existia mais de um professor de Física na escola, todo o nosso material foi passado para esse profissional. Uma das professoras foi convidada a dar uma aula para os colegas professores sobre como estava trabalhando em sala de aula. A repercussão dessa aula foi muito positiva em relação à coordenação e à direção, mas houve uma rejeição de seus colegas professores. O que estava sendo apresentado era muito diferente do ensino que eles executavam.

A tese de doutorado de Capecchi (2004) analisou como a cultura científica foi disponibilizada no plano social da sala de aula através de atividades de experimentação e interações entre professora e alunos nas aulas. As interações em sala de aula foram abordadas a partir de uma análise multimodal dos modos de construção de significados (verbal, oral e escrito; gestos e ações; visual) empregados por alunos e professora na construção de explicações. Essa análise descreveu como se desenvolveu a construção dos principais aspectos da cultura científica identificados nas aulas. Entre esses se destacaram as diversas inscrições literárias (a construção dos dados numéricos e de tabelas) e discussões envolvendo habilidades de argumentação.

O mestrado de Carmo (2006) estudou as outras etapas do laboratório investigativo, desde a passagem dos dados de tabelas para linguagem gráfica, incluindo a verificação dos potenciais e limitações de tabelas, e da passagem da linguagem gráfica para a algébrica, possibilitando a generalização dos resultados a partir da equação fundamental da calorimetria. Nesse processo, como ocorre na Ciência (Roth, \& Lawless, 2002), a professora criou condições para que os estudantes olhassem as diversas linguagens matemáticas das quais a Física se apropria, de forma semelhante à que fazem os físicos, ou seja, como se fosse uma "lente" para enxergar o fenômeno.

Essa formação não surtiu o efeito que desejávamos: a expansão do ensino por investigação. Mas, os tempos mudaram, nosso livro foi reeditado quinze anos depois. Atualmente, com as novas Bases Nacionais Comum Curriculares, é bem possível que o 
resultado da formação dos professores seja outro. Entretanto, os resultados das pesquisas sobre o ensino e a aprendizagem em um ensino por investigação ainda são válidos e têm nos mostrado que estamos no caminho certo.

\section{Pesquisas Sobre o Comportamento da Luz}

As pesquisas de ensino, aprendizagem e formação de professores tornaramse mais complexas para os conceitos de Mecânica Quântica, pois cada novo conceito depende de pré-requisitos que muitas vezes os alunos não possuem e, para engloba-los, as SEI ficam grandes, o que requer que tenhamos muito cuidado para manter o foco. O grupo do LAPEF enfrentou esse problema elaborando duas SEI que deram origem a pesquisas de ensino e aprendizagem e de formação de professores.

O mestrado de Barrelo Jr. (2010) adaptou uma sequência de ensino elaborada no LAPEF modificando as atividades para um ensino por investigação. Como professor da Escola de Aplicação, ele pesquisou como se desenvolve o processo argumentativo dos alunos sobre o conceito de fóton e se os estudantes se apropriam das interpretações da Mecânica Quântica para a natureza e o comportamento da luz. Para tanto, utilizou um interferômetro real e em uma extrapolação para o ideal, além do arranjo experimental de Mach-Zehnder e de um programa de computador que simula esse experimento. As gravações foram feitas em duas turmas do terceiro ano do ensino médio. Para responder às questões de pesquisa foram analisadas as aulas que sistematizavam as discussões e os registros escritos finais dos alunos. A partir dos dados, foi possível verificar a ocorrência de indicadores de alfabetização científica, caracterizar a estrutura do discurso oral dos alunos e a apropriação das interpretações da Mecânica Quântica sobre a natureza da luz por estudantes de ensino médio.

A tese de doutorado de Barrelo Jr (2015) teve como objetivo principal a generalização dos resultados encontrados no mestrado na aplicação da SEI em escolas estaduais com professores comprometidos com o ensino e a aprendizagem de seus alunos. Ele propôs um curso de formação em serviço para quatro professores que se prontificaram a aplicar a SEI em suas classes. Na tese, foram analisadas as aulas de dois professores. A partir dos dados obtidos não foi possível verificar a ocorrência de indicadores de alfabetização científica nem a estrutura do discurso oral dos alunos, embora os registros escritos demonstrem a apropriação de conceitos de Física Moderna e Contemporânea pelos estudantes.

O curso de formação foi estudado por Almeida (2014) em seu mestrado. A partir do referencial teórico do Ensino por Investigação, foram buscadas as ideias que os professores empregam ao planejar e aplicar a SEI. Isto foi feito a partir da análise das reuniões de planejamento entre alguns professores que se propuseram a aplicar uma SEI sobre "Dualidade da Luz" e o formador, que já havia trabalhado com esta sequência anteriormente. Durante estas reuniões, buscamos observar quais ideias principais sobre o Ensino por Investigação surgiam durante as conversas que seriam importantes para a aplicação das atividades. Os resultados sugerem a importância de o professor aplicador 
da SEI possuir algumas ideias que serão imprescindíveis para que essa metodologia possa, de fato, ocorrer (o que está de acordo com os resultados da pesquisa de Gonçalves (1997) para a formação de professores para o ciclo Fundamental). Os resultados também mostram o quão difícil é fazer com que o professor rompa com o paradigma vigente do ensino tradicional e consiga entender e aplicar uma inovação metodológica, o Ensino por Investigação, em sala de aula.

A segunda SEI foi elaborada por Lopes (2013), que a denominou "E o elétron? É onda ou é partícula?”. Esta SEI tem por objetivo promover a ocorrência da alfabetização científica no contexto de Física Moderna e Contemporânea em estudantes do ensino médio. Ela é constituída por três experiências demonstrativas que dão base para a discussão de três textos elaborados pelo autor da dissertação a partir de textos originais: entrevista com J. J. Thomson; entrevista com G. P. Thomson; e entrevista com A. Tonomura. Como os textos originais são de difícil compreensão para os alunos da Escola Média, Lopes reescreveu os principais tópicos dos textos em forma de entrevista. Deste modo, os novos conceitos e explicações foram introduzidos com as palavras dos próprios físicos. Além de conter instruções propriamente ditas, materiais e atividades a serem desenvolvidas, a SEI possui uma parte com orientações destinadas a professores que adotem esse material instrucional, bem como as justificativas teóricas e bases conceituais adotadas como referência para seu desenvolvimento e seus propósitos didáticos.

Tendo por base as aulas de Lopes, Saca (2017) organizou um arranjo experimental bastante interessante: gravou a aula e entrevistou o professor antes e depois desta. Isto foi feito com o objetivo de compreender como a participação do professor no discurso contribui para a obtenção de seus objetivos em aulas investigativas. Saca identificou três tipos de conteúdos: conceitos da ciência, técnicas da ciência e natureza e inter-relações da ciência. A participação do professor nesses três tipos de conteúdos foi muito grande, apresentando e desenvolvendo as ideias sendo que as interações foram exclusivamente do discurso didático. Entretanto quando a SEI apresentava os problemas para os alunos resolverem, foi identificada uma mudança na forma de agir do professor, que passou a oferecer elementos e pistas que os alunos deveriam considerar, havendo, nesses momentos, interação aluno/aluno. Esta SEI ainda não foi testada com outros professores que não o próprio autor.

\section{SEI sobre quantidade de movimento, sua conservação e as leis de Newton}

Bellucco (Bellucco, \& Carvalho 2014) organizou uma SEI sobre quantidade de movimento, sua conservação e as leis de Newton. Essa sequência serviu de base para uma pesquisa que visava compreender o papel da matemática na construção dos argumentos dos estudantes em atividades de ensino investigativas (Bellucco, 2015). Para alcançar estes objetivos, foram analisadas as gravações em vídeo da aplicação desta sequência em uma turma do primeiro ano do ensino médio de uma escola pública do estado de Santa Catarina. O professor que se prontificou a utilizar a sequência em suas aulas foi bastante diretivo, o que acarretou pouca participação dos alunos. Ela está sendo novamente 
aplicada e em breve teremos novos dados para serem analisados e discutidos.

\section{Conclusões das Pesquisas em Formação de Professores para um Ensino Investigativo nos Graus Fundamental I e Médio}

Foram poucas as pesquisas que realizamos sobre a formação de professores no nível médio. Entretanto, analisando os resultados dessas investigações a partir de todo o conhecimento sistematizado e descrito nas pesquisas em ensino, aprendizagem e formação de professores realizadas pelo LaPEF, podemos propor o seguinte problema:

Por que as Sequências de Ensino Investigativas (SEI) para o Ensino Fundamental são replicadas em grande escala com os mesmos resultados que encontramos em nossas pesquisas e isso não acontece com as SEI organizadas para o Ensino Médio?

Temos duas hipóteses para discutir este problema:

Quando definimos as SEI, mostramos que a diretriz principal de uma atividade investigativa é o cuidado do(a) professor(a) com o grau de liberdade intelectual dado ao aluno e com a elaboração do problema. Minha hipótese é a de que estes dois fatores diferenciam o trabalho do professor(a) do Fundamental do trabalho do(a) professor(a) do nível Médio.

Os problemas propostos nas atividades investigativas de ciências para o Ensino Fundamental I são bastante simples do ponto de vista científico, dando condições para as professoras (mesmos as generalistas) se sentirem seguras de trabalhar com eles. A proposta pedagógica das atividades investigativas, dando liberdade intelectual aos alunos, é bastante familiar a essas professoras, o que facilita sua utilização em sala de aula. Trabalhando com a mesma classe todos os dias e, portanto, conhecendo bem seus alunos, a professora do Fundamental I tem condições de ter uma forte interação professor/aluno o que facilita a nova proposta de liberdade intelectual aos estudantes. Além disso, e as condições de trabalho na escola, especialmente a possibilidade de discutir seus problemas de ensino com suas colegas que 'falam a mesma língua' nas reuniões pedagógicas, é um suporte à introdução de inovação.

Os problemas propostos nas atividades investigativas das Ciências (Física, Química e Biologia) para o ensino médio são mais complexos (tanto os de laboratório, como os problemas abertos e as questões de história das ciências), pois são construídos para abranger o ensino e a aprendizagem das várias linguagens das ciências: escrita, oral, gráfica e a matemática. Para facilitar a construção e o ensino desses problemas, seria importante que os professores conhecessem os problemas que originaram a construção dos conhecimentos científicos, em especial, quais foram as dificuldades e obstáculos epistemológicos (o que constitui uma ajuda para entender as dificuldades dos alunos) e também conhecer as orientações metodológicas empregadas na construção dos conhecimentos (Carvalho, \& Gil-Perez 1993). Isso é muito difícil, pois a história das ciências abrange vários séculos de construção de conhecimento. Para serem resolvidos 
pelos alunos, mesmo no nível 3 de liberdade intelectual, esses problemas exigem uma participação diferenciada dos professores. É preciso que eles orientem a argumentação de seus alunos por meio de perguntas didáticas (por exemplo, visando o estimulo à participação), científicas (relacionadas a técnicas da Ciência) e epistêmicas (voltadas para a construção de significados). Será que isso foi/é discutido em seus cursos de formação?

A interação professor/aluno, que é base para a liberdade intelectual do aluno, também não é facilitada para a maioria de nossos professores que, com poucas aulas por semana em cada turma e com grande número de estudantes por turma, têm poucas chances de conhecer cada um de seus alunos. Ao contrário das professoras do Fundamental I, um professor de ciências do nível Médio quase sempre é o único professor de Física, Química ou Biologia da escola, não tendo, portanto, com quem trocar ideias e fazer comentários durante a aplicação de uma inovação pedagógica.

Nessas condições de trabalho, a maioria dos professores do nível médio, não podendo alcançar os dois conceitos básicos do ensino por investigação - organização de problemas e liberdade intelectual para os alunos - têm grande dificuldade de trabalhar com as sequências de ensino investigativo, mesmo que sejam eles os próprios autores das sequências.

\section{Referências}

Abrahão, T. C. (2004). A formação de professores de ciências para o ensino fundamental. (Dissertação de Mestrado em Ensino de Ciências), Universidade de São Paulo, São Paulo.

Afonso, A. M. (2011). Alfabetização Científica dos alunos e as ações do professor que corroboram com este processo. (Dissertação de Mestrado em Ensino de Ciências), Universidade de São Paulo, São Paulo.

Almeida, A. G. F. (2014). As ideias balizadoras necessárias para o professor planejar e avaliar a aplicação de uma Sequência de Ensino Investigativa. (Dissertação de Mestrado em Ensino de Ciências), Universidade de São Paulo, São Paulo.

Barrelo Junior, N. (2010). Argumentação no discurso oral e escrito de alunos do ensino médio em uma sequência didática de Física Moderna. (Dissertação de Mestrado em Educação). Universidade de São Paulo, São Paulo.

Barrelo Junior, N. (2015). Promovendo a argumentação em sala de aula de física moderna e contemporânea: uma sequência de ensino investigativa e as interações professor-alunos. (Tese de Doutorado em Ensino de Física), Universidade de São Paulo, São Paulo.

Bastos, A. P. S. (2017). Potenciais Problemas Significadores em aulas investigativas: contribuições da perspectiva histórico-cultural. (Tese de Doutorado em Educação), Universidade de São Paulo, São Paulo. 
Bellucco, A. C., \& Carvalho, A. M. P. (2014). Uma proposta de sequência de ensino investigativa sobre quantidade de movimento, sua conservação e as leis de Newton. Caderno Brasileiro de Ensino de Física, 31, 30-59.

Bellucco, A. C. (2015) Argumentação matemática em aulas investigativas de física. (Tese de Doutorado em Educação), Universidade de São Paulo, São Paulo.

Borges, A. T. (2004). Novos rumos para o laboratório escolar de ciências. Caderno Brasileiro de Ensino de Física, 21(Especial), 9-30.

Briccia, V., \& Carvalho, A. M. P. (2016). Competência e Formação Docente dos Anos Iniciais para Educação Científica. Ensaio: Pesquisa e Educação em Ciências, 18(1), 1-22.

Capecchi, M.C.M.(2004).Aspectos da Cultura Científicaem Atividadesde Experimentação nas Aulas de Física. (Tese de Doutorado em Educação), Universidade de São Paulo, São Paulo.

Carmo, A. B. (2006). Contemplando a cultura científica na sala de aula: um olhar sobre os alunos. (Dissertação de Mestrado em Educação), Universidade de São Paulo, São Paulo.

Carvalho, A. M. P. (2010). As condições de diálogo entre professor e formador para um ensino que promova a enculturação científica dos alunos. In A. Dalben, J. Diniz, L. Leal, L. Santos (Org.). Convergência e Tensões no Campo do Trabalho Docente, (pp. 281-300). Belo Horizonte: Autêntica

Carvalho, A. M. P. (2013) Ensino de Ciências por Investigação: Condições de implementação em sala de aula. São Paulo: Cengage Learning.

Carvalho, A. M. P., Barros, M. A., Gonçalves, M. E. R., Rey, R. C., \& Vannucchi, A I. (1998). Conhecimento Físico no Ensino Fundamental. São Paulo: Scipione. Recuperado de www.lapef.fe.uso.br.)

Carvalho, A. M. P., \& Gil-Pérez, D. (1993). Formação de Professores de Ciências. São Paulo: Cortez.

Carvalho, A. M. P., Oliveira, C., Sasseron. L. H., Sedano L., \& Batistoni M. (2011) Investigar e Aprender Ciências, 5 volumes, São Paulo: Editora Sarandi.

Carvalho, A. M. P., Ricardo, E. C., Sasseron, L. H., Abib, M. L. V. S., \& Pietrocola, M. (2010) Ensino de Física. São Paulo; Cengage Learning.

Carvalho, A M. P, Santos, E. I., Azevedo, M. C. P. S., Date, M. P. S., Fujii, S. R. S., \& Nascimento, V. B. (1999). Termodinâmica: um ensino por investigação. São Paulo: Editora da USP.

Carvalho, A. M. P., Santos E. I., Azevedo M. C. P. S., Date, M. P. S., Fujii, S. R. S., \& Briccia, V. (2014). Calor e temperatura: um ensino por investigação. São Paulo: Editora da Física. 
Castro, R. S. (1993). História e Epistemologia da Ciência: Investigando suas Contribuições num Curso de Física de Segundo Grau. (Dissertação de Mestrado em Educação), Universidade de São Paulo, São Paulo.

Cilurzo, A. B. (2002). Parceria Universidade Escola: da retórica à realidade: uma escuta na sua conversa. (Dissertação de Mestrado em Ensino de Ciências). Universidade de São Paulo, São Paulo.

Couto, F. P., \& Aguiar Junior, O. (2009). Sustentando o Interesse e Engajamento dos Estudantes: Análise do Discurso em Atividade Demonstrativa de Física. Trabalho apresentado no VII Encontro Nacional de Pesquisa em Educação em Ciências, Florianópolis.

Drive, R., Newton, P., \& Osborne, J. (1999). The place of argumentation in the pedagogy of school science. International Journal of Science Education, 21(5), 556-576.

Driver, R., Guesne, E., \& Tiberghien, A. (1985). Children's ideas in science. Milton Keynes: Open University Press. Tradução de P. Manzano, 1989 Ideas científicas en la infancia y la adolescencia. Madrid: Morata/MEC.

Freiberg, H. L. (2015). Elementos Catalisadores para a promoção da Negociação de Sentidos. (Dissertação de Mestrado em Educação), Universidade de São Paulo, São Paulo.

Gonçalves, M. E. R. (1997). As atividades de conhecimento físico na formação do professor das séries iniciais. (Tese de Doutorado em Educação), Universidade de São Paulo, São Paulo.

Gonçalves, M. E. R. (1991). O Conhecimento Físico nas Primeiras Séries do Primeiro Grau. (Dissertação de Mestrado em Educação), Universidade de São Paulo, São Paulo.

Inhelder, B. Y., \& Piaget, J. (1976). Da Lógica da Criança à Lógica do Adolescente. Tradução de Dante Moreira Leite. São Paulo: Pioneira.

Jiménez-Aleixandre, M. P., (2005). A argumentação sobre questões sociocientíficas: processos de construção e justificação do conhecimento na aula. Trabalho apresentado no V Encontro Nacional de Pesquisa em Educação em Ciências, Bauru.

Jiménez-Aleixandre M. P., \& Crujeiras, B. (2017). Epistemic Practices and Scientific Practices in Sciences Education. In K. S. Taber, and B. Akpan. Science Education: An International Course Companion (pp.69-80). Switzerland: Springer Nature.

Kelly, G. J. (2008). Inquiry, activity and epistemic practice. In R. A. Duschl, \& R. E. Grandy. Teaching Scientific Inquiry: Recommendations for research and implementation. (pp. 288-291). Rotterdam: Sense Publishers.

Latour B., \& Woolgar, S. (1997). A vida de laboratório: a produção de fatos científicos. Rio de Janeiro: Relume Dumará.

Lawson, A. E. (2001). Using the learning cycle to teach biology concepts and reasoning patterns. Journal of Biology Education, 35(4), 165-169. 
Lawson, A. E. (2000a). How do humans acquire knowledge? And what does that imply about the nature of knowledge? Science \& Education, 9(6), 577-598.

Lawson, A. E. (2000b). The generality of hypothetic-deductive reasoning: Making scientific reasoning explicit. The American Biology Teacher, 62(7), 482-495.

Lemke, J. (1998a). Multiplying meaning: visual and verbal semiotics in scientific text. In J. Martin, and R. Veel (Eds.), Reading Science. London: Routledge.

Lemke, J. (1998b). Teaching all the languages of Science: words, symbols, images and actions. Available at http:http://academic.brooklyn.cuny.edu/education/jlemke/sci-ed. htm

Lemke, J. (2000). Multimedia literacy demands of the scientific curriculum. Linguistics and Education, 10(3), 247-271.

Locatelli, R. J. (2006). O raciocínio hipotético preditivo e o pensamento proporcional no ensino de Ciências. (Dissertação de Mestrado em Ensino de Ciências), Universidade de São Paulo, São Paulo.

Lopes, E. DE S. (2013). E o Elétron? É Onda ou é Partícula? - Uma proposta para promover a ocorrência da alfabetização científica de física moderna e contemporânea em estudantes do ensino médio. (Dissertação de Mestrado em Ensino de Ciências), Universidade de São Paulo, São Paulo.

Magie, W. F. (1935). Source Book in Physics. New York: McGraw-Hill.

Matthews, M. R. (1991). Un lugar para la histoira y la filosofia en la enseñaza de las ciencias. Comunication, Lenguaje y Educación, 11(12), 141-155.

Nascimento, V. B. (2003). Visões de Ciências e Ensino por Investigação. (Dissertação de Mestrado em Educação), Universidade de São Paulo, São Paulo.

Nascimento, V. B. (2012). Competências docentes em um projeto de inovação para a educação científica. (Tese de Doutorado em Educação), Universidade de São Paulo, São Paulo.

Oliveira, C. M. A. (2003). Escrevendo em aulas de ciências. (Dissertação de Mestrado em Ensino de Ciências), Universidade de São Paulo, São Paulo.

Padilha, J. N. (2008). O uso das palavras e gestos durante a construção dos conceitos de sombra e reflexão nas aulas de conhecimento Físico. (Dissertação de Mestrado em Ensino de Ciências), Universidade de São Paulo, São Paulo.

Paiva, J. R. (2015). Múltiplas representações na construção do conhecimento científico escolar. (Tese de Doutorado em Ensino de Ciências), Universidade de São Paulo, São Paulo

Pella, M. O. (1969). The Laboratory and Science Teaching. In H. O. Andersen. Reading in Science Education for the Secondary School. London: MacMillan. 
Piaget, J. (1978). Fazer e compreender. São Paulo: Melhoramentos/Edusp.

Piaget, J., \& Garcia R. (1984). Psicogênesis e história de la ciencia. 2. ed. Cidade do México: Siglo Veintiuno Editores.

Piaget, J. (1977). A tomada de consciência. São Paulo: Melhoramentos/Edusp.

Rey, R. C. (2000). Um Estudo da Causalidade Física em Atividades de Ensino, (Dissertação de Mestrado em Educação), Universidade de São Paulo, São Paulo.

Richardson, R. J. (2009). Pesquisa Social: Métodos e técnicas. $3^{\text {a }}$ ed. São Paulo: Atlas.

Rodrigues, M. I. R. (2001). Professores Pesquisadores: Reflexão e a Mudança Metodológica no Ensino da Termodinâmica. (Dissertação de Mestrado em Educação), Universidade de São Paulo, São Paulo.

Roth, W. M., \& Lawless, D. (2002). Science, Cultura, and Emergence of Language. Science \& Education, 86(30), 368-385.

Saca, L. Y. (2017). Discurso e Aspectos Epistêmicos: Análise de aulas de Ensino por Investigação. (Dissertação de Mestrado em Ensino de Ciências), Universidade de São Paulo, São Paulo.

Sasseron, L. H. (2005). Em busca de influências culturais na investigação e na explicação de atividades de Conhecimento Físico por alunos indígenas. (Dissertação de Mestrado em Ensino de Ciências), Universidade de São Paulo, São Paulo.

Sasseron, L. H. (2008). Alfabetização científica no ensino fundamental: estrutura $e$ indicadores deste processo em sala de aula. (Tese de Doutorado em Educação), Universidade de São Paulo, São Paulo.

Sasseron, L. H., Nascimento, V. B., \& Carvalho, A. M. P. (2009). O uso de textos históricos visando a Alfabetização Científica. In M. H. R. Beltran, F. Saito, R. N. Santos, \& W. Wrou. História da Ciência e Ensino: Propostas, tendências e construção de interfaces. São Paulo: Ed Livraria da Física.

Sasseron, L. H., \& Carvalho, A. M. P. (2008). Almejando a Alfabetização Científica no Ensino Fundamental: A proposição e a procura de indicadores do processo. Investigações em Ensino de Ciências, 13(3), 333-352.

Sedano, L. (2010). Compreensão Leitora nas Aulas de Ciências. (Tese de Doutorado em Educação), Universidade de São Paulo, São Paulo.

Sedano, L. S. (2005). Ensino de Ciências e Formação da Autonomia Moral. (Dissertação de Mestrado em Educação), Universidade de São Paulo, São Paulo.

Tinoco, S. C. (2000). A Mudança nas Concepções dos Professores sobre Aprendizagem de Ciências. (Dissertação de Mestrado em Educação) Universidade de São Paulo, São Paulo. 
Yin, R. K. (2010). Estudo de Caso: Planejamento e Métodos. 4a Edição. Porto Alegre: Bookman.

Anna Maria Pessoa de Carvalho

${ }^{\circ}$ https://orcid.org/0000-0003-2671-3810

Universidade de São Paulo

Faculdade de Educação

LaPEF - Laboratório de Pesquisa e Ensino de Física

São Paulo, Brasil

ampdcarv@usp.br

Submetido em 22 de Janeiro de 2018 Aceito em 16 de Junho de 2018

Publicado em 30 de Julho de 2018 